\title{
Scalpel can achieve better clinical outcomes compared with electric cautery in primary total knee arthroplasty: a comparison study
}

\author{
Wei Lin, Yike Dai, Jinghui Niu, Guangmin Yang, Ming Li and Fei Wang*
}

\begin{abstract}
Background: Whether using the scalpel can provide better and faster recovery after the primary total knee arthroplasty (TKA) is still controversial. The aim of this research was to compare the clinical outcomes of using the scalpel and the electric cautery in primary TKA.

Methods: From January 2016 to December 2017, a retrospective cohort study was conducted in 313 patients who underwent unilateral primary TKA by using the scalpel (group S). During this period, we selected 313 patients who underwent unilateral primary TKA by using the electric cautery (group E) for comparison. The tourniquet time, operative time, blood loss, wound complications, visual analog score for pain, range of motion, Knee Society Score were assessed between the two groups. The Forgotten Joint Score was used to analyze the ability to forget the joint.

Results: There were no significant differences in tourniquet time, operative time, blood loss between the two groups $(p>0.05)$. In the group $S$, the visual analog score for pain, range of motion, Knee Society Score were found better results at 1 week, 1 month, 3 months, 6 months, 12 months and 24 months after surgery $(p<0.05)$. Besides, during the follow-up period, the Forgotten Joint Score was significantly higher compared with group $\mathrm{E}(p<0.05)$.

Conclusion: In this research, the patients who underwent TKA by using the scalpel could achieve better clinical outcomes. In addition, if forgotten artificial joint after TKA was the final goal, the patients who underwent TKA by using the scalpel would acquire better quality of life.
\end{abstract}

Keywords: Scalpel, Electric cautery, Forgotten joint score, Total knee arthroplasty

\section{Background}

More than 100 million people around the world are affected by osteoarthritis (OA) [1]. It is a chronic disease, the knee joint is the most severely affected joint, and there is no doubt that total knee arthroplasty (TKA) is the most effective surgical method for the treatment of end-stage knee OA [2]. The main advantages of TKA are to relieve

\footnotetext{
* Correspondence: doctorlinw@163.com

Department of Orthopedic Surgery, Third Hospital of Hebei Medical University, No. 139 Ziqiang Road, Shijiazhuang 050051, Hebei, People's Republic of China
}

the pain of the knee, improve the knee function, restore lower limb alignment, and improve the quality of life of patients [3]. In the process of TKA, some surgeons like to use the scalpel and others like to use the electric cautery to expose the articular cavity. However, which of these two methods is better is still controversial.

In the past 10 years, many surgeons believe that using the electric cautery can reduce blood loss during surgery, so there is a tendency to use electric cautery instead of the scalpel $[4,5]$. But many experienced orthopaedic surgeons still prefer to use the scalpel to cut

(c) The Author(s). 2020 Open Access This article is licensed under a Creative Commons Attribution 4.0 International License, which permits use, sharing, adaptation, distribution and reproduction in any medium or format, as long as you give appropriate credit to the original author(s) and the source, provide a link to the Creative Commons licence, and indicate if changes were made. The images or other third party material in this article are included in the article's Creative Commons licence, unless indicated otherwise in a credit line to the material. If material is not included in the article's Creative Commons licence and your intended use is not permitted by statutory regulation or exceeds the permitted use, you will need to obtain permission directly from the copyright holder. To view a copy of this licence, visit http://creativecommons.org/licenses/by/4.0/. The Creative Commons Public Domain Dedication waiver (http://creativecommons.org/publicdomain/zero/1.0/) applies to the data made available in this article, unless otherwise stated in a credit line to the data. 
skin and soft tissue quickly and efficiently to complete the TKA [6]. The electric cautery is one of the conventional instruments in surgery, and it has the advantages of good hemostatic effect, convenient and simple operation, etc. The unipolar electric cautery is a traditional device that transfers current through a resistance wire electrode to generate heat, which is used for tissue coagulation [7]. Although using the electric cautery in surgery is very effective, it has the potential to cause complications. At the end of the twentieth century, the incidence of electrosurgical injuries remained at about 2 to 5 per 1000 people $[8,9]$. One study discovered that using electric cautery during surgery resulted in poor wound healing and high wound infection rates [10]. Some studies have noted that using the electric cautery during surgery not only increases the cost of the operation, but also generates a lot of harmful smoke during the operation, which affects the health of the surgical staff $[11,12]$. Because the electric cautery generates a lot of heat, mistakes in operation may lead to more soft tissue damage $[13,14]$.

We found few studies comparing the clinical outcomes in primary TKA by using the electric cautery or the scalpel. Consequently, we conducted a retrospective, and case matched research to compare the clinical outcomes between the two methods, with a follow-up of at least 2 years. We assumed that using the scalpel might achieve better clinical outcomes compared to the electric cautery in primary TKA.

\section{Methods}

With the approval of the Institutional Review Committee, we performed a retrospective case-matched study from January 2016 to December 2017. Three hundred thirteen patients who underwent unilateral primary TKA by using the scalpel from January 2016 to December 2016 were included in group S. From January 2017 to December 2017, we selected 313 patients who underwent unilateral primary TKA by using the electric cautery (group E) for comparison. To improve the reliability of this research, the two groups matched in a 1:1 ratio based on age, sex, body mass index (BMI), and followup time. Inclusion criteria were (1) unilateral primary knee osteoarthritis; (2) flexion-contracture deformity < $20^{\circ}$; (3) varus deformity $<20^{\circ}$. Patients who had valgus or stiff knee, neurological problems, anticoagulant therapy, revision TKA, inflammatory arthritis, or previous open knee surgery were excluded. All surgeries were performed in our center by the same senior orthopaedic surgeon.

\section{Surgical technique}

In the two groups, the skin was incised with a scalpel, 10 $\mathrm{mg} / \mathrm{kg}$ dose of tranexamic acid (TXA) was administered intravenously to all patients before surgery, and after the implant was placed, $2.0 \mathrm{~g}$ TXA mixed with $100 \mathrm{ml}$ of normal saline directly into the surgical site and soaked in the solution for $2 \mathrm{~min}$ [15]. According to the patient's physical condition, using hypotensive anesthesia with low mean arterial pressures. All surgeries were accomplished through the medial parapatellar arthrotomy, and pneumatic tourniquets were used during surgeries to help stop bleeding. In the group S, we used scalpel number 22 (Jinhuan $^{\circ}$ surgical blade, Jinhuan medical supplies Co., Ltd., Shanghai Pudong, China) for the midline skin incision, and then scalpel number 10 (Jinhuan surgical blade, Jinhuan medical supplies Co., Ltd., Shanghai Pudong, China) to dissect the sub-fascial layers and opened the joint cavity by the incision of the medial retinacular tissue. Then release the medial deep collateral ligament. The synovium, meniscus and anterior cruciate ligament were removed. Some major small blood vessels around the knee joint did not coagulate, and the tourniquet was released when the wound was closed. In group E, using the same number scalpel for the midline skin incision. Then, using electric cautery (Peng's Multifunctional Operational Dissectors (PMOD), Co., Ltd., Zhengjiang Shuyou, China), set at $65 \mathrm{~W}$ coagulation mode, to separate and cut the soft tissues in the knee joint cavity mentioned above. After the implant was placed, the tourniquet was released, and the bleeding points were coagulated by the electric cautery during the surgery. All patients received the same type of knee prosthesis (CR, Mobile bearing, LINK, Germany, Gemini MK II) and postoperative treatment options, including rehabilitation programs and pain control.

\section{Outcome evaluation}

The assessments were conducted by a senior orthopaedic surgeon who did not participate in the treatment. Patients demographics in regard to age, sex, BMI, follow-up time, operative time, tourniquet time, blood loss, wound complications were examined. Routine blood tests were performed 1 day before and 1 day after surgery to avoid the effect of perioperative infusion on the test results.

The range of motion (ROM), visual analog score (VAS) for pain, Knee Society Score (KSS) [16] were assessed. For comparing the postoperative status of the patients who received TKA via the two different methods, we used the Forgotten Joint Score (FJS; a 12-item questionnaire with a maximum of 100) to analyze the ability to forget the joint [17]. Higher scores represented better results. All data were assessed at 1 week, 1 month, 3 months, 6 months, 12 months, and 24 months after surgery.

\section{Statistical analysis}

All statistical data were used the Shapiro-Wilks test to check the normality of continuous variables. If the data 
were normally distributed, the two groups would be compared using t-test; if not, the non-parametric test would be performed. And the Fisher's exact test was performed for categorical variables. The correlation between the FJS score and surgery method (scalpel versus electric cautery), sex, gender and BMI were analyzed by multiple linear regression. The data were analyzed with the SPSS 19.0 (IBM, Chicago, Illinois, USA). $p<0.05$ was considered statistically significant.

\section{Results}

All patients in both groups were followed up at least 2 years. No significant differences were found between the two groups in regard to age, sex, BMI, ROM, VAS, KSS, operative time, blood loss, tourniquet time before surgery $(p>0.05)$ (Tables 1,2$)$. Wound complications accounted for 2 cases $(0.6 \%)$ in group S; 9 cases $(2.9 \%)$ in group $\mathrm{E}(p=0.033)$. No revision surgery was performed in either group.

In the group $\mathrm{S}$, the results of VAS, ROM, and KSS were better than those in the group $\mathrm{E}$ at 1 week, 1 month, 3 months, 6 months, 12 months and 24 months after surgery $(p<0.05)$ (Tables 3,4$)$. Furthermore, during follow-up, the FJS score in group $\mathrm{S}$ was significantly higher than that in group $\mathrm{E}(p<0.05)$ (Table 5). The multiple linear regression showed that higher FJS score was correlated with the scalpel method $(p<0.05)$ (Table 6).

\section{Discussion}

The most significant finding in this research was that the patients who underwent TKA by using the scalpel could achieve better clinical outcomes. In addition, if forgotten artificial joint after TKA was the final goal, the patients who underwent TKA by using the scalpel would acquire better quality of life.

Blood loss is an major problem in the process of TKA, which will cause many related complications. TXA has been suggested as a treatment option to reduce blood loss during TKA. Some studies have indicated that the intravenous use of TXA in the perioperative period has

Table 1 Patients demographics in the two groups

\begin{tabular}{llll}
\hline Demographics & Group S & Group E & $p$-value \\
\hline Total patients & 313 & 313 & - \\
Age (years) & $68.1 \pm 4.2$ & $67.3 \pm 5.2$ & 0.532 \\
BMI $\left(\mathrm{kg} / \mathrm{m}^{2}\right)$ & $26.7 \pm 4.2$ & $27.4 \pm 3.2$ & 0.491 \\
Sex & & & 0.845 \\
Male & $66(21.1 \%)$ & $68(21.7 \%)$ & - \\
Female & $247(78.9 \%)$ & $245(78.3 \%)$ & - \\
Side (right/left) & $170 / 143$ & $162 / 151$ & 0.442 \\
Follow-up time (years) & $2.1 \pm 0.3$ & $2.2 \pm 0.4$ & 0.661 \\
\hline
\end{tabular}

BMI Body mass index; mean \pm standard deviation
Table 2 Postoperative clinical results in the two groups

\begin{tabular}{llll}
\hline Results & Group S & Group E & -value \\
\hline Operative time (min) & $82.9 \pm 10.1$ & $81.6 \pm 10.4$ & 0.457 \\
Tourniquet time (min) & $38.1 \pm 3.4$ & $37.8 \pm 3.6$ & 0.341 \\
Pre-operative haemoglobin (g/dL) & $12.4 \pm 1.2$ & $12.1 \pm 1.6$ & 0.281 \\
Post-operative haemoglobin (g/dL) & $10.3 \pm 1.1$ & $10.2 \pm 1.6$ & 0.128 \\
Pre-operative hematocrit (\%) & 42.1 & 43.3 & 0.361 \\
Post-operative hematocrit & 36.2 & 35.8 & 0.413 \\
wound complications & $2(0.6 \%)$ & $9(2.9 \%)$ & 0.033 \\
\hline
\end{tabular}

mean \pm standard deviation

achieved significant effects in reducing blood loss [18, 19]. Similarly, studies have confirmed that topical use of TXA can obtain similar clinical effects as intravenous use of TXA, and the less possibility of complications [20, 21]. In addition, other studies have pointed out that the topical use of the hemostatic agent, such as Floseal ${ }^{\circ}$, has achieved significant results in controlling blood loss during TKA [22-25]. In the present study, in order to reduce the related complications caused by blood loss, all of our patients have combined intravenous and topical use of TXA. Most surgeons believed that, like abdominal surgery [26] and spinal surgery [27], electric cautery could reduce blood loss during TKA. In present study, we did not calculate the estimated blood loss by weighing the gauze and calculating the amount of liquid in the suction bottle. Instead, we adopted a method mentioned in the previous article [28], the blood loss was compared between the two groups by comparing haemoglobin,

Table 3 The VAS and ROM in the two groups

\begin{tabular}{llll}
\hline Results & Group S & Group E & p-value \\
\hline VAS & & & \\
Preop & $5.1 \pm 1.4$ & $4.9 \pm 1.6$ & 0.351 \\
Postop 1 week & $3.9 \pm 1.8$ & $4.3 \pm 1.6$ & 0.042 \\
Postop 1 month & $3.6 \pm 1.1$ & $4.3 \pm 1.7$ & 0.039 \\
Postop 3 months & $3.3 \pm 1.2$ & $4.1 \pm 1.1$ & 0.041 \\
Postop 6 months & $2.8 \pm 1.3$ & $3.6 \pm 1.4$ & 0.032 \\
Postop 12 months & $2.3 \pm 1.4$ & $2.6 \pm 1.2$ & 0.047 \\
Postop 24 months & $2.1 \pm 1.1$ & $2.2 \pm 1.4$ & 0.029 \\
ROM & & & \\
preop & $95.1 \pm 7.7$ & $96.2 \pm 7.9$ & 0.713 \\
Postop 1 week & $102.6 \pm 9.8$ & $97.9 \pm 8.9$ & 0.036 \\
Postop 1 month & $105.6 \pm 7.2$ & $98.9 \pm 7.8$ & 0.032 \\
Postop 3 months & $107.8 \pm 7.3$ & $100.9 \pm 5.4$ & 0.043 \\
Postop 6 months & $108.1 \pm 8.2$ & $104.3 \pm 9.8$ & 0.046 \\
Postop 12 months & $110.6 \pm 7.1$ & $109.9 \pm 5.8$ & 0.021 \\
Postop 24 months & $115.2 \pm 8.2$ & $114.9 \pm 6.8$ & 0.037 \\
\hline VAS Visual anague score for pain: $R 0 M$ Range of motion:Preop Preoperation
\end{tabular}

VAS Visual analogue score for pain; ROM Range of motion; Preop Preoperation; Postop Postoperation; mean \pm standard deviation 
Table 4 The KSS scores in the two groups

\begin{tabular}{llll}
\hline Results & Group S & Group E & $p$-value \\
\hline Clinical score & & & \\
preop & $36.4 \pm 5.2$ & $36.1 \pm 4.6$ & 0.781 \\
Postop 1 week & $52.1 \pm 8.8$ & $47.3 \pm 7.2$ & 0.041 \\
Postop 1 month & $72.4 \pm 6.7$ & $67.6 \pm 5.9$ & 0.038 \\
Postop 3 months & $79.6 \pm 6.9$ & $74.3 \pm 4.7$ & 0.031 \\
Postop 6 months & $82.4 \pm 5.7$ & $78.6 \pm 5.9$ & 0.041 \\
Postop 12 months & $88.1 \pm 3.7$ & $87.6 \pm 3.1$ & 0.046 \\
Postop 24 months & $92.5 \pm 4.7$ & $91.3 \pm 4.9$ & 0.039 \\
Functional score & & & \\
preop & $37.1 \pm 5.4$ & $38.6 \pm 3.9$ & 0.713 \\
Postop 1 week & $48.6 \pm 8.3$ & $44.1 \pm 7.6$ & 0.031 \\
Postop 1 month & $65.2 \pm 6.8$ & $61.1 \pm 5.7$ & 0.026 \\
Postop 3 months & $71.1 \pm 5.8$ & $67.4 \pm 4.2$ & 0.035 \\
Postop 6 months & $76.4 \pm 4.2$ & $72.1 \pm 3.8$ & 0.046 \\
Postop 12 months & $81.1 \pm 3.8$ & $80.2 \pm 3.2$ & 0.025 \\
Postop 24 months & $85.6 \pm 3.6$ & $84.1 \pm 3.4$ & 0.044 \\
\hline
\end{tabular}

KSS Knee Society Score; Preop Preoperation; Postop Postoperation; mean \pm standard deviation

hematocrit before and after surgery. It has known that one unit of blood loss has an effect of $3 \%$ on hematocrit levels and $1 \mathrm{~g} / \mathrm{dL}$ on hemoglobin. In our research, we found that there was no significant difference in the hemoglobin levels and hematocrit whether using the electric cautery or the scalpel. Perhaps it was related to the tourniquet, tranexamic acid, and hypotensive anesthesia with low mean arterial pressures during surgery. Furthermore, Tammachote et al. [11] believed that the main cause of intraoperative blood loss might be due to osteotomy and femoral medullary hemorrhage during surgery.

Postoperative wound infection is one of the most severe complications after TKA. The causes of infections are diverse, for example, incision hematoma, contaminated incisions, and less stringent aseptic procedures. Although we used broad-spectrum antibiotics to prevent this problem, we had not got satisfactory results. Some

Table 5 The FJS scores in the two groups

\begin{tabular}{llll}
\hline Results & Group S & Group E & $p$-value \\
\hline Postop 1 week & $44.9 \pm 8.3$ & $40.2 \pm 8.6$ & 0.046 \\
Postop 1 month & $57.4 \pm 5.7$ & $50.6 \pm 8.9$ & 0.038 \\
Postop 3 months & $62.6 \pm 5.1$ & $55.4 \pm 7.5$ & 0.026 \\
Postop 6 months & $71.3 \pm 4.6$ & $65.6 \pm 5.3$ & 0.035 \\
Postop 12 months & $78.4 \pm 3.7$ & $70.6 \pm 6.9$ & 0.039 \\
Postop 24 months & $81.2 \pm 3.4$ & $78.1 \pm 4.7$ & 0.041 \\
\hline
\end{tabular}

FJS Forgotten Joint Score; Preop Preoperation; Postop Postoperation; mean \pm standard deviation
Table 6 Multiple linear regression analysis

\begin{tabular}{llll}
\hline & Coefficient & $95 \%$ Cl & $p$-value \\
\hline Scalpel method & 39.8 & 26.2 to 74.1 & 0.029 \\
Electric cautery method & 29.1 & 22.6 to 61.3 & 0.157 \\
Age & 0.735 & 0.216 to 1.314 & 0.652 \\
BMl & -0.684 & -1.227 to -0.517 & 0.071 \\
Sex & 0.618 & -1.318 to 3.262 & 0.738 \\
\hline BMl Body mass index;
\end{tabular}

BMI Body mass index; Cl Confidence interval

studies have pointed out [29-31] that electric cautery may cause delayed wound healing and histological indicate that tissue damage from electric cautery can easily cause tissue damage and increase the infection rate of the incision site. In addition, previous researches have reported that the inflammatory response at the wound affects early functional exercise after joint replacement $[32,33]$. And, the damage caused by electric cautery to surrounding tissues may be the main factor leading to the inflammatory response $[13,14]$. These findings were consistent with our study that higher wound complications were found by using the electric cautery after TKA. In order to prevent surgical site infection and wound complications, the Centers of Disease Control and Prevention has put forward prevention guidelines [34]. In addition, as an alternative to traditional dressings, negative-pressure wound therapy (NPWT) has been used to effectively treat open wounds in various situations [35, 36]. Recently, there is increasing evidence that closed incisional NPWT (ciNPWT) can potentially reduce the risk of surgical site infection, wound complications, reoperation, and decreased length of hospitalization in patients with TKA [37-39]. Although we did not use this kind of ciNPWT in our study, it might be a better choice when we encounter severe wound complications in the future.

The FJS is a newly developed scoring system in recent years, which is often used to measure patients' ability to forget joint replacement or joint awareness in daily life. Even if the patient's knee function is improved and no pain is felt, the FJS score will be lower if the patient is "aware of" the presence of artificial joints in daily life. As a result, minor complaints that are not identified by specific issues (such as "Can you do sports?") are called "aware" joints, which may reduce the ceiling effect and more sensitively reflect postoperative quality of life [17, 40]. Ozaki et al. believed that FJS is a scoring system that can express "sense of stability" as "awareness" [41]. Morten et al. believed that FJS combines factors such as stiffness, pain, the ability of daily activities, and patients' expectations to reflect patients' ability to forget artificial joints in activities, so this scoring system may be the best tool to evaluate the results of TKA [42]. Another study found that when using the FJS scoring system to evaluate the difference in knee awareness of patients who 
underwent patellofemoral arthroplasty, unicompartmental knee arthroplasty and TKA treatment, they found that patients who underwent different joint arthroplasties had very large differences in the FJS [43]. In the present study, we found higher FJS score by using the scalpel after TKA, and this might mean that the patients had a higher quality of life.

Increased potential smoke plume risk is another risk factor of electric cautery $[11,12]$. Surgical smoke exposure may increase the risk of acute or chronic lung diseases such as pneumonia or asthma. One study noted that in Mexico, as a result of exposure to electric cautery smoke, many surgical surgeries developed lump (58\%) and sore throat (22\%) in the throat [44]. Some studies have also shown that perioperative nurses have twice as many respiratory diseases as asthma, bronchitis, allergies, and sinus infections in the general population $[45,46]$. Therefore, for the safety of patients and medical staff, we should pay more attention to the problem of smoke generated by electric cautery during surgery. However, a previous study pointed out that traditional surgeries with the scalpel were more cost-effective than the electric cautery [11]. Therefore, we recommended that using the ordinary scalpel as much as possible when performing primary TKA.

The limitation of this research was that it had a retrospective short-term follow-up design, which has its potential weaknesses. A prospective and long-term research should be performed to confirm these findings.

\section{Conclusion}

In this research, the patients who underwent TKA by using the scalpel could achieve better clinical outcomes. In addition, if forgotten artificial joint after TKA was the final goal, the patients who underwent TKA by using the scalpel would acquire better quality of life.

\section{Abbreviations}

TKA: Total knee arthroplasty; VAS: Visual analog score; ROM: Range of motion; KSS: Knee society score; FJS: Forgotten joint score; OA: Osteoarthritis;

BMl: Body mass index; TXA: Tranexamic acid

\section{Acknowledgments}

The authors would like to thank all the staff of the participating departments.

\section{Authors' contributions}

FW designed the study. WL, YKD, and JHN performed the experimental work. GMY, ML, and WL evaluated the data. WL wrote the manuscript. All authors read and approved the final manuscript.

\section{Funding}

Not applicable.

\section{Availability of data and materials}

The detailed data and materials of this study are available from the corresponding author via e-mail on reasonable request.

\section{Ethics approval and consent to participate}

This study was approved by the Third Hospital of Hebei Medical University and followed the Declaration of Helsinki. Written informed consent was obtained from all the patients.

\section{Consent for publication}

Not applicable.

\section{Competing interests}

The authors declare that they have no competing interests.

Received: 1 May 2020 Accepted: 24 June 2020

Published online: 29 June 2020

\section{References}

1. Murray CJ, Vos T, Lozano R, et al. Disability-adjusted life years (DALYs) for 291 diseases and injuries in 21 regions, 1990-2010: a systematic analysis for the global burden of disease study 2010. Lancet, 2012;380(9859):2197-223.

2. Roberts VI, Esler CN, Harper WM. A 15-year follow-up study of 4606 primary total knee replacements. J Bone Joint Surg Br. 2007:89(11):1452-6.

3. Liabaud B, Patrick DA Jr, Geller JA. Is the posterior cruciate ligament destabilized after the tibial cut in a cruciate retaining total knee replacement? An anatomical study. Knee. 2013;20(6):412-5.

4. Plymale MF, Capogna BM, Lovy AJ, Adler ML, Hirsh DM, Kim SJ. Unipolar vs bipolar hemostasis in total knee arthroplasty: a prospective randomized trial. J Arthroplasty. 2012;27(6):1133-7.e1.

5. Marulanda GA, Krebs VE, Bierbaum BE, Goldberg VM, Ries M, Ulrich SD, Seyler TM, Mont MA. Hemostasis using a bipolar sealer in primary unilateral total knee arthroplasty. Am J Orthop (Belle Mead NJ). 2009;38(12):E179-83.

6. Yagishita K, Muneta T, Ikeda H. Step-by-step measurements of soft tissue balancing during total knee arthroplasty for patients with varus knees. J Arthroplast. 2003;18(3):313-20.

7. Massarweh NN, Cosgriff N, Slakey DP. Electrosurgery: history, principles, and current and future uses. J Am Coll Surg. 2006;202(3):520-30.

8. Nduka CC, Super PA, Monson JR, Darzi AW. Cause and prevention of electrosurgical injuries in laparoscopy. J Am Coll Surg. 1994;179(2):161-70.

9. Hulka JF, Levy BS, Parker WH, Phillips JM. Laparoscopic assisted vaginal hysterectomy: American Association of Gynecologic Laparoscopists' 1995 membership survey. J Am Assoc Gynecol Laparosc. 1997:4(2):167-71.

10. Ji GW, Wu YZ, Mei GH, et al. Experimental and clinical study of influence of high-frequency electric surgical knives on healing of abdominal incision. World J Gastroenterol. 2006;12(25):4082-5.

11. Tammachote N, Kanitnate S. Electric cautery does not reduce blood loss in primary total knee arthroplasty compared with scalpel only surgery a double-blinded randomized controlled trial. Int Orthop. 2018;42(12):275560.

12. Okoshi K, Kobayashi K, Kinoshita K, Tomizawa Y, Hasegawa S, Sakai Y. Health risks associated with exposure to surgical smoke for surgeons and operation room personnel. Surg Today. 2015;45(8):957-65.

13. Cadeddu JA. Re: lateral temperature spread of monopolar, bipolar and ultrasonic instruments for robot-assisted laparoscopic surgery. J Urol. 2015; 193(1):129.

14. Taheri A, Mansoori P, Sandoval LF, Feldman SR, Pearce D, Williford PM. Electrosurgery: part I. Basics and principles. J Am Acad Dermatol. 2014;70(4): 591.e1-591.e14.

15. Patel JN, Spanyer JM, Smith LS, Huang J, Yakkanti MR, Malkani AL. Comparison of intravenous versus topical Tranexamic acid in Total knee Arthroplasty: a prospective randomized study. J Arthroplast. 2014;29(8): 1528-31.

16. Insall JN, Dorr LD, Scott RD, Scott WN. Rationale of the knee society clinical rating system. Clin Orthop Relat Res. 1989:(248):13-4.

17. Behrend H, Giesinger K, Giesinger JM, Kuster MS. The "forgotten joint" as the ultimate goal in joint arthroplasty: validation of a new patient-reported outcome measure. J Arthroplasty. 2012;27(3):430-436.e1.

18. Kurtz S, Ong K, Lau E, Mowat F, Halpern M. Projections of primary and revision hip and knee arthroplasty in the United States from 2005 to 2030. J Bone Joint Surg Am. 2007;89(4):780-5.

19. Losina E, Thornhill TS, Rome BN, Wright J, Katz JN. The dramatic increase in total knee replacement utilization rates in the United States cannot be fully explained by growth in population size and the obesity epidemic. J Bone Joint Surg Am. 2012;94(3):201-7. 
20. Wang $H$, Shen $B$, Zeng Y. Comparison of topical versus intravenous tranexamic acid in primary total knee arthroplasty: a meta-analysis of randomized controlled and prospective cohort trials. Knee. 2014;21(6):98793.

21. Wang S, Gao X, An Y. Topical versus intravenous tranexamic acid in total knee arthroplasty: a meta-analysis of randomized controlled trials. Int Orthop. 2017:41(4):739-48.

22. Helito CP, Bonadio MB, Demange MK, et al. Comparison of floseal ${ }^{\circledR}$ and tranexamic acid for bleeding control after total knee arthroplasty: a prospective randomized study. Clinics (Sao Paulo). 2019;74:e1186.

23. Helito CP, Gobbi RG, Castrillon LM, Hinkel BB, Pécora JR, Camanho GL. Comparison of Floseal(r) and Electrocautery in hemostasis after Total knee Arthroplasty. Acta Ortop Bras. 2013;21(6):320-2.

24. Fu X, Tian P, Xu GJ, Sun XL, Ma XL. Thrombin-based hemostatic agent in primary Total knee Arthroplasty. J Knee Surg. 2017;30(2):121-7.

25. Wang C, Han Z, Ma XL, et al. The efficacy of a thrombin-based hemostatic agent in primary Total knee Arthroplasty: a meta-analysis. J Orthop Surg Res. 2014;9:90.

26. Liao G, Wen S, Xie X, Wu Q. Harmonic scalpel versus monopolar electrocauterization in cholecystectomy. JSLS. 2016;20(3):e2016.00037.

27. Hill SE, Broomer B, Stover J, White W, Richardson W. Bipolar tissue sealant device decreases hemoglobin loss in multilevel spine surgery. Transfusion. 2012;52(12):2594-9.

28. Ozturk K, Kaya L, Turhal G, Akyildiz S. A comparison of electrothermal bipolar vessel sealing system and electrocautery in selective neck dissection. Eur Arch Otorhinolaryngol. 2016;273(11):3835-8.

29. Groot G, Chappell EW. Electrocautery used to create incisions does not increase wound infection rates. Am J Surg. 1994;167(6):601-3.

30. Soballe PW, Nimbkar NV, Hayward I, Nielsen TB, Drucker WR. Electric cautery lowers the contamination threshold for infection of laparotomies. Am J Surg. 1998;175(4):263-6.

31. Kumagai SG, Rosales RF, Hunter GC, Rappaport WD, Witzke DB, Chvapil TA Chvapil M, Sutherland JC. Effects of electrocautery on midline laparotomy wound infection. Am J Surg. 1991;162(6):620-2 discussion 622-3.

32. Ugras AA, Kural C, Kural A, Demirez F, Koldas M, Cetinus E. Which is more important after total knee arthroplasty: local inflammatory response or systemic inflammatory response? Knee. 2011;18(2):113-6.

33. Hall GM, Peerbhoy D, Shenkin A, Parker CJ, Salmon P. Relationship of the functional recovery after hip arthroplasty to the neuroendocrine and inflammatory responses. Br J Anaesth. 2001;87(4):537-42.

34. Mangram AJ, Horan TC, Pearson ML, Silver LC, Jarvis WR. Guideline for prevention of surgical site infection, 1999. Centers for Disease Control and Prevention (CDC) hospital infection control practices advisory committee. Am J Infect Control. 1999, 27:97e132 quiz 3-4; discussion 96.

35. Schlatterer DR, Hirschfeld AG, Webb LX. Negative pressure wound therapy in grade IIIB tibial fractures: fewer infections and fewer flap procedures? Clin Orthop Relat Res. 2015:473:1802e11.

36. Cooper HJ, Bas MA. Closed-incision negative-pressure therapy versus antimicrobial dressings after revision hip and knee surgery: a comparative study. J Arthroplast. 2016;31:1047e52.

37. Kim JH, Kim HJ, Lee DH. Comparison of the efficacy between closed incisional negative-pressure wound therapy and conventional wound management after Total hip and knee Arthroplasties: a systematic review and meta-analysis. J Arthroplast. 2019;34(11):2804-14.

38. Helito CP, Bueno DK, Giglio PN, Bonadio MB, Pécora JR, Demange MK Negative-pressure wound therapy in the treatment of complex injuries after total knee arthroplastY. Acta Ortop Bras. 2017;25(2):85-8.

39. Karlakki SL, Hamad AK, Whittall C, Graham NM, Banerjee RD, Kuiper JH. Incisional negative pressure wound therapy dressings (iNPWTd) in routine primary hip and knee Arthroplasties: a randomised controlled trial. Bone Joint Res. 2016:5(8):328-37.

40. Hamilton DF, Giesinger JM, MacDonald DJ, et al. Responsiveness and ceiling effects of the forgotten joint Score-12 following total hip arthroplasty. Bone Joint Res. 2016:5(3):87-91.

41. Ozaki Y, Baba T, Kaneko K, et al. Posterior versus direct anterior approach in total hip arthroplasty: difference in patient-reported outcomes measured with the forgotten joint Score-12. Sicot J. 2018;4:54

42. Thomsen MG, Latifi R, Kallemose T, Husted H, Troelsen A. Does knee awareness differ between different knee arthroplasty prostheses? A matched, case-control, cross-sectional study. BMC Musculoskelet Disord. 2016;01(17):141.
43. Thienpont E, Opsomer G, Koninckx A, Houssiau F. Joint awareness in different types of knee arthroplasty evaluated with the forgotten joint score. J Arthroplast. 2014;29:48-51.

44. Navarro-Meza MC, Gonzalez-Baltazar R, Aldrete-Rodriguez MG, CarmonaNavarro DE, Lopez-Cardona MG. Respiratory symptoms caused by the use of electrocautery in physicians being trained in surgery in a Mexican hospital. Rev Peru Med Exp Salud Publica. 2013;30(1):41-4.

45. Ball K. Compliance with surgical smoke evacuation guidelines: implications for practice. Ornac J. 2012;30(1):14-6 18-9, 35-7.

46. Ball K. Surgical smoke evacuation guidelines: compliance among perioperative nurses. AORN J. 2010;92(2):e1-23.

\section{Publisher's Note}

Springer Nature remains neutral with regard to jurisdictional claims in published maps and institutional affiliations.
Ready to submit your research? Choose BMC and benefit from:

- fast, convenient online submission

- thorough peer review by experienced researchers in your field

- rapid publication on acceptance

- support for research data, including large and complex data types

- gold Open Access which fosters wider collaboration and increased citations

- maximum visibility for your research: over $100 \mathrm{M}$ website views per year

At BMC, research is always in progress.

Learn more biomedcentral.com/submissions 